\title{
Applying data mining techniques for spatial distribution analysis of plant species co-occurrences
}

Luís Alexandre Estevão da Silva ${ }^{1}$, Marinez Ferreira de Siqueira ${ }^{1}$, Flávia dos Santos Pinto ${ }^{1}$, Felipe Sodré Barros $^{1}$, Geraldo Zimbrão da Silva ${ }^{2}$, Jano Moreira de Souza ${ }^{2}$

\author{
${ }^{1}$ Instituto de Pesquisas Jardim Botânico do Rio de Janeiro, Brazil \\ ${ }^{2}$ COPPE/UFRJ, Universidade Federal do Rio de Janeiro, Brazil
}

\{estevao, marinez\}@jbrj.gov.br, \{flaviasantospinto, felipe.b4rros\}@gmail.com, \{zimbrao, jano\}@cos.ufrj.br

\begin{abstract}
The continuous growth of biodiversity databases has led to a search for techniques that can assist researchers. This paper presents a method for the analysis of occurrences of pairs and groups of species that aims to identify patterns in co-occurrences through the application of association rules of data mining. We propose, implement and evaluate a tool to help ecologists formulate and validate hypotheses regarding cooccurrence between two or more species. To validate our approach, we analyzed the occurrence of species with a dataset from the 50-ha Forest Dynamics Project on Barro Colorado Island (BCI). Three case studies were developed based on this tropical forest to evaluate patterns of positive and negative correlation. Our tool can be used to point co-occurrence in a multi-scale form and for multi-species, simultaneously, accelerating the identification process for the Spatial Point Pattern Analysis. This paper demonstrates that data mining, which has been used successfully in applications such as business and consumer profile analysis, can be a useful resource in ecology.
\end{abstract}

Index Terms: Data analysis; data mining; association rules; knowledge management applications; knowledge discovery

\section{Introduction}

Amounts of available data have grown exponentially in recent years, causing discussions about the need for new methods to access, analyze and manage biological data (Howe et al., 2008), (Xindong Wu, Zhu, Wu, \& Ding, 2014); one example is the Global Biodiversity Information Facility (Gbif, 2010). Databases on scientific collections have accompanied the increase in data, partly as a consequence of the need to obtain a shorter response time for research in biology and also due to the concern for biodiversity conservation. However, analysis of existing patterns in such large data sources has become a challenge, particularly for a few researchers who are needed for multiple studies in the area (Hopkins \& Freckleton, 2002), (Drew, 2011).

The difficulty in the extraction of knowledge from large databases has been perceived by many sectors of the economy, and much of the research has identified data mining as an efficient way to extract knowledge from these sources (Han, Kamber, \& Pei, 2011), (Aggarwal, 2015). It has been used successfully in areas such as customer relationship management, to analyze and build prediction models in the commercial area (Nettleton, 2014); education, predicting the success rate of students enrolled in courses (Natek \& Zwilling, 2014), (Peña-Ayala, 2014); text mining (Zhao, Cen, Javaheri, Sepehri, \& Teimourpour, 2014); internet security (Abdelhamid, Ayesh, \& Thabtah, 2014), among other areas. In 
ecology, its use has been increasing in applications, indicating potential uses of data mining (Hochachka et al., 2007); comparing and using classification algorithms to predicting the potential habitat of species (Pino-Mejías et al., 2010), (Lorena et al., 2011), (Dlamini, 2011); cluster analysis to identify regions with similar ecological conditions (Kumar, Mills, Hoffman, \& Hargrove, 2011) or grouping species into disjunct sets with similar co-association values using $k$-means clustering algorithm (Flügge, Olhede, \& Murrell, 2014); and for forest growing stock modelling with decision tree algorithm (Debeljak, Poljanec, \& Ženko, 2014). But the adoption has been slower than the previously mentioned fields (Inman-Narahari, Giardina, Ostertag, Cordell, \& Sack, 2010).

In addition to the large volumes of data, other difficult issues have demanded the work of ecologists, among which the study of plant communities (Baselga \& Araújo, 2010) is notable for involving complex process analysis (Swenson, 2013) given that little is known of the processes governing the composition of plant communities (Uriarte, Condit, Canham, \& Hubbell, 2004), particularly in tropical forests that are complex ecosystems where many species coexist (Johnson, Domínguez-García, Donetti, \& Muñoz, 2014). In this context, one of the most important ecological relationships between any species is their co-occurrence (Neeson \& Mandelik, 2014). These interactions can be of positive (Monge \& Gornish, 2014) or negative (Veech, 2014) type, such as facilitation and segregation, respectively. Quantifying this relationship between species allows several studies as selection of indicator species (Culmsee et al., 2014) and many other analyses in conservation ecology.

Spatial Points Process are defined as set of observations $\left(\mathrm{X}^{1}, \mathrm{X}^{2}, \ldots, \mathrm{X}^{3}\right)$ within study area 'A', where each point has at least a pair of coordinates (Lloyd, 2006). Others information can be associated, like species identification, elevation, collector, among other. This process is distance based and, analyze the spatial structure rather than its variation thru the space. Thus, it is possible to infer spatial association in a univariate (one points process. i.e: one species) or bivariate spatial point process (two different point process; two i.e: species). Among the methods, stands out Ripley's K-function (Ripley, 1977) that is commonly applied in plant ecology to detect the spatial distribution of individuals within communities and the underlying processes controlling the observed patterns (Haase, 1995), (Zhang, Hu, Zhu, \& Ni, 2012). The K-function estimates (Bivand, Pebesma, \& Gómez-Rubio, 2008) the expected number of events found in a given distance $(t)$ of each point or event and constructing ever-increasing concentric circles of radius $t$, as follows (Lancaster \& Downes, 2004):

$$
\mathrm{Kt}=\mathrm{n}-2 \text { Ainj } \neq \text { inwij It (dij) }
$$

As above, $n$ is the total number of events; $w_{i j}$ is a weighting factor to correct edge effects; $A$ is the study plot area; $I_{t}$ is a counter which is set to 1 if the distance $d_{i j}$ between the $i^{\text {th }}$ and $j^{\text {th }}$ points (pairwise mode) is less than or equal to $t$, otherwise is equal $0 . K(t)$ is presented as the linearized L-function $\mathrm{L}(\mathrm{t})=$ $[\mathrm{K}(\mathrm{t}) / \pi]^{1 / 2}$, as proposed by Besag (Besag, 1977). Under Complete Spatial Randomness $(\mathrm{CSR}), \mathrm{L}(\mathrm{t})=0$; values of $\mathrm{L}(\mathrm{t})>0$ indicate attraction between the two events; values less than 0 indicate repulsion.

However, the application of these techniques by bivariate form requires a full pairwise comparison, which is usually not practical in multivariate event sets (Perry, Miller, \& Enright, 2006). This difficulty affects the type of application in analysis mainly in a megadiversity context. Another problem is the limited ability to separate scales (Detto \& Muller-Landau, 2013), failing to demonstrating whether, for example, deviations from complete spatial randomness at small distances are due to causes acting at small scales or at larger scales (Loosmore \& Ford, 2006). Another initiative is the kdot function (Baddeley \& Turner, 2005) that investigates the relationship of co-occurrence of a point (species) to any point (species) in space. However, this approach does not allows identify which species have cooccurrence, which is another differential of data mining techniques presented in our approach. 
Given the scenario presented and also considering that ecologists have long been researching effective methods (Veech, 2013) to understand the mechanisms of coexistence, competition and distribution of species (Wiegand et al., 2012) and, despite all the progress achieved in data mining area after studying the traditional methods used in ecology for the analysis of point patterns, we found no research using association rules with inventory plots data in ecological applications, which has motivated this study. Thus we offer a method for the analysis multi-scale form and for multi-species associated with the environment to assist ecologists in the assessment of patterns of occurrences of species in plant communities. This method is also based on the need for research with a larger number of variables to explain the occurrences in an environment as diverse as the tropical forest. Therefore, this study considers a new type of application of association rules in the investigation of patterns of occurrences of species' pairs and groups and emphasizes that the development of a specific method for extracting knowledge from biodiversity databases is necessary, given the large volumes of data available.

\section{Association Rules}

Notable among the categories in data mining is Association Rules (Agrawal, Imieliński, \& Swami, 1993), which aims to discover frequently appearing items from a set of transactions, deriving rules from associations among the items involved in each transaction (X. Wu et al., 2008) without implying causality (Tan, 2007). A transaction corresponds to the set of items in an operation, such as products purchased by a particular customer for market basket analysis (Brin, Motwani, \& Silverstein, 1997). The format of a rule can be exemplified as a logical statement between two items, $A$ (antecedent) and $B$ (consequent), as $s p_{-} A \rightarrow s p_{-} B$, and can be comprehended as a pattern where $s p_{-} A$ and $s p_{-} B$ appear together. A pattern is interesting if it helps define a hypothesis, and an interesting pattern represents knowledge. This category of data mining is also used in such areas as business management (Cil, 2012), consumer profile analysis (Liao, Chen, \& Deng, 2010), recommender systems (Lazcorreta, Botella, \& Fernández-Caballero, 2008), (Adomavicius \& Tuzhilin, 2005), adverse drug reactions (Ji et al., 2013) and genetics (Lin, Huang, \& Leu, 2011).

\subsection{Notations and definitions}

This study adapted the association rules to be used in data plots obtained from floristic inventories, or a method for assessment distribution of plant species in a local area, where the area is divided into plots of equal size. Several inventory protocols are used according to the purpose of the work (Gordon \& Newton, 2006) and formalized as follows: a) a set of items (itemset) is a subset of the set of specimens (individuals) from all species examined, and $b$ ) each transaction is composed of all specimens within the specified distance (radius in meters) of a given specimen. To illustrate, Table 1 presents transactions involving six supposed species found near five trees identified by the attribute Treeid from 1 to 5 .

Table 1

Example with five transactions and six species.

\begin{tabular}{|c|c|}
\hline Treeid & Items \\
\hline 1 & $\mathrm{sp} \_1, \mathrm{sp} \_2$ \\
\hline 2 & $\mathrm{sp}_{1} 1, \mathrm{sp}_{-} 3, \mathrm{sp}_{4} 4, \mathrm{sp}_{-} 5$ \\
\hline 3 & $\mathrm{sp}_{2} 2, \mathrm{sp}_{-} 3, \mathrm{sp}_{-} 4, \mathrm{sp}_{-} 6$ \\
\hline 4 & $\mathrm{sp}_{1} 1, \mathrm{sp}_{2} 2, \mathrm{sp}_{-} 3, \mathrm{sp}_{-} 4$ \\
\hline 5 & $\mathrm{sp}_{-} 1, \mathrm{sp} \_2, \mathrm{sp} \_3, \mathrm{sp} \_6$ \\
\hline
\end{tabular}


Several metrics can be used to evaluate the quality of the rules generated by algorithms of association rules. We used the following set of measures: support, confidence, lift (Han et al., 2011); chi-square (Hahsler, Gruen, \& Hornik, 2005) and p-value (G. Liu, Zhang, \& Wong, 2011). The first two measures were used to define the species' pairs and groups, the third to evaluate the association type (positive or negative) and the last two to assess the degree of independence of the species. For example, considering two species $s p_{-} A$ and $s p_{-} B$, the support is the probability $P$ of transactions with both species and is defined as support $\left(s p_{-} A \rightarrow s p \_B\right)=P\left(s p_{-} A \cup s_{-} B\right)$. The confidence is defined as the frequency with which items are found in the transaction $s p_{-} A$ containing $s p \_B$ and is defined as the conditional probability conf $\left(s p_{-} A \rightarrow s p_{-} B\right)=P\left(s p_{-} A \mid s p_{-} B\right)$. The lift is the measure of importance of a rule and can be defined by $P\left(s p_{-} A \cup s p_{-} B\right) /\left(P\left(s p_{-} A\right) * P\left(s p \_B\right)\right)$. Their values can be interpreted in the following ways. A value equal to one indicates independence between the antecedent and the consequent of the rule. A value greater than one means that the items have a positive correlation. In other words, the appearance of items with a frequency higher than expected and a value less than one indicates a negative association. Based on the values in Table 1, the support value is the result of the division of the number of transactions $n$ with sp_3 and sp_4 (treeid $=2,3$ and 4) by the total transactions, resulting in $3 / 5=0.6$, which indicates that two species occur together in $60 \%$ of the transactions. The confidence of the rule can also be calculated by support $\left(s p_{-} A \rightarrow s p \_B\right) / s p \_A$, contain $s p \_A$ (treeid $=2,3,4$ and 5$)$, or $(0.6 / 0.8)=0.75$, indicating that $\mathrm{sp}_{-} 2$ was found when $\mathrm{sp}_{-} 1$ was present $75 \%$ of the time. The lift is equal to confidence $\left(s p_{-} A \rightarrow s p_{-} B\right) / s p \_B$, or $0.75 /(3 / 5)=$ 1.25. Another metric used was the chi-square. Its use was defined to better evaluate the results obtained with the lift. A value of zero implies the statistical independence of the variables. A value greater than a certain threshold indicates that the antecedent and the consequent of the rule have no independence. Acceptable values for independence range from 0.05 to 3.84 (B. Liu, Hsu, \& Ma, 1999). When used in association rules, a low $p$-value indicates that a rule has a low chance of occurring if the antecedent and consequent are independent. A high value indicates a rule has a high chance of occurring if no association exists between the items.

\section{Material and methods}

\subsection{Data set}

The data used in this study are from the floristic inventory of the Forest Dynamics Project (FDP) plot of Barro Colorado Island (BCI), Panama (99' N, 7951' W) (Hubbell, Condit, \& Foster, 2005), (Hubbell, 1999). The BCI 50-ha plot was established in 1980, and all trees and shrubs with diameter at breast height $(\mathrm{DBH})$ greater than 10 millimeters in the plot were mapped. It can be divided into five habitat types (Harms, Condit, Hubbell, \& Foster, 2001). The database consists of 277,351 records, for a total 312 species and the data used comes from the 2010 census. Surveys with this measure have been conducted at 5-year intervals since 1985. This study selected specimens with DBH greater than 100 millimeters, which allowed us to search for co-occurrence patterns in already established individuals and seek more robust results with more than 20 points of occurrence. This threshold allowed us to select species with minimum frequency equal to 0.001 in the case study at the distance of 5 meters (small scale) and 0.02 with 20 meters (larger scale). Similar distances were used in previous studies (Lan et al., 2012). These filters reduced the number of species to 117 .

\subsection{The method}




\subsubsection{Overview}

To perform the association analysis, data must be prepared in the proper format. With this objective, we developed a method initially based on the observation that great variation may exist in the distance between two specimens in a plot. According to the definition of the value of the distance, different types of studies can be performed.

For example, one study to identify the preferred habitats of species with a value of up to 20 meters and another analyzing competition between species with 5 meters or less could be conducted. It depends on the scale in which these processes occur. Given these considerations and searching for accurate results, the proposed method calls for the definition of the distance to be used in research and from this definition, the Euclidean distance between all the pairs of specimens in the database can be calculated. Because several possibilities may occur regarding the distribution of species in the plot, the evaluation of the distance between the points of occurrence may be more accurate than the simple identification of the plot in some situations.

Thus, Fig. 1 displays examples of the distribution of points with only two plots displayed, where the letters $A$ through $G$ indicate the species and numbers indicate the specimens. The distance setting allows the analysis of cases such as what happens when two specimens are located a few meters apart but in different plots, such as instances $D_{3}$ in $P 1$ and $E_{1}$ in $P 2$. In these cases, analyses that consider the plots sampling units would not identify that type of association. Another possible case is that in which two species occur in greater abundance when they are nearby (co-occurrences), as indicated by the points of species $A$ and $B$, both in $P 1$ and $P 2$, suggesting that these species may signify a particular type of habitat. The opposite is presented between $F$ and $G$, suggesting a negative correlation.

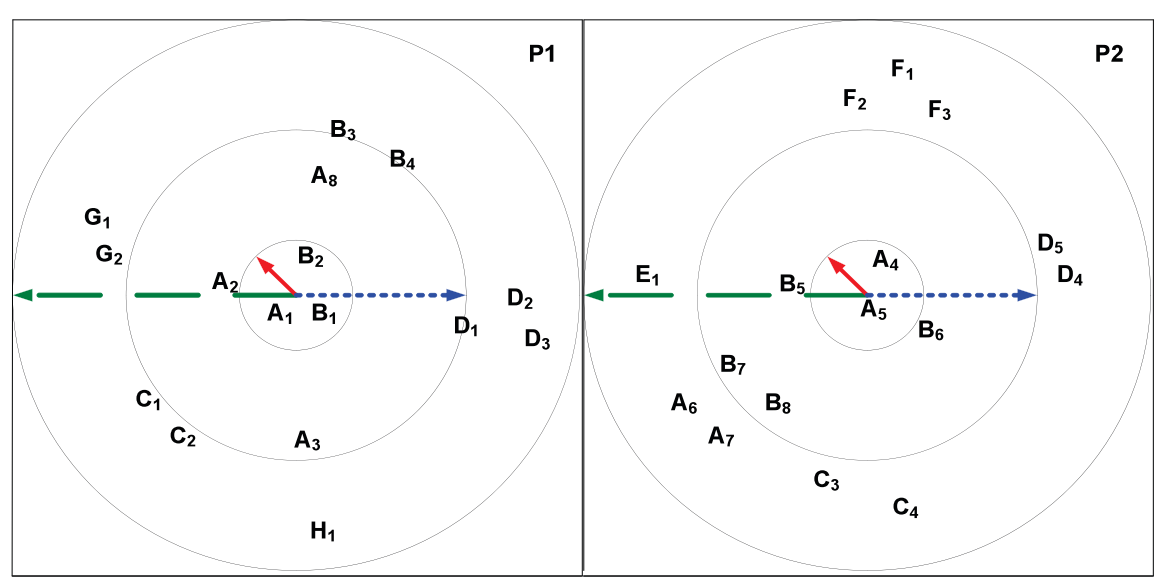

Fig. 1. Overview of occurrences of the species. The red arrows indicate a radius of up to 2.5 meters around two occurrences centred on different plots, P1 and P2, up to 5 meters (as indicated with blue arrows) and up to 10 meters (as indicated with green arrows).

Considering the nature of the application and the possibility of several specimens near each other, the transaction, which is a unit of application of the association analysis, may contain many items (specimens), resulting in the difficulty in determining the frequent items and the generation of rules. Therefore, we selected the Apriori algorithm (C. C. Aggarwal, Zhao, \& Yu, 2010), (P. W. P. Wang, Shi, Bai, \& Zhao, 2009), which suggests that all subsets of a set of frequent items must also be frequent, with the same approach being used for infrequent items. It allows the algorithm to decrease the numbers of candidate items in the generation of rules, accelerating the processing. The application of the algorithm requires setting the value support, defined as the ratio between the numbers of times two 
species occur together and the total possible pairs of species in the community. Because the process depends on the number of records, it is important to note the frequency of the species analyzed. High support values may exclude species with a low occurrence frequency and limit the analysis to the most common species. Only 12 species with relative frequency above 0.5 at 20 meters are selected from an initial total of 117 .

\subsubsection{First stage: Data set preparation}

The method is divided into two stages (Fig. 2). The first stage aims to prepare data for the association analysis algorithm, where records containing specimens that satisfy the specified distance for the radius in meters are converted into the format needed for the application of Apriori. The calculation of the distance between occurrence points is performed in the fifth step of the method, and it was possible because the location of each specimen in the plot was determined by the $x$ and $y$ coordinates, according to the mapping method described in Condit (Condit, 1998). The first stage includes the following steps:

(1) Selection of species by the applications of filters. For example, one selection criteria can be used with $\mathrm{DBH}>100$ millimeters;

(2) Setting the maximum distance $D$ (in meters) between the specimens as parameters of application;

(3) Reading the values of one point of species $i$ to be analyzed for each occurrence of the species $i$ and using coordinates $\left(G i_{x}, G i_{y}\right)$;

(4) Reading values of one point of species $j$ to be analyzed for each occurrence of the species $j$ and using coordinates $\left(G j_{x}, G j_{y}\right)$;

(5) Calculation of the distance Euclidean $D i j$ for all other specimens (represented by $j$ ) in the database using $D_{i j}=\left[\left(G i_{x}-G j_{x}\right)^{2}+\left(G i_{y}-G j_{y}\right)^{2}\right]^{1 / 2}$;

(6) Transformation of data into a required transactional format for application of algorithm Apriori and inclusion of results in the table Transactions. Table 2 presents the results of the application of the proposed method for four trees, generating four transactions, then allowing the application of association analysis in different distances.

Table 2

Example with four transactions obtained from the units represented in Fig. 2.

\begin{tabular}{clc}
\hline Treeid & Items & Distance \\
\hline G1 & sp_G & 5 \\
B1 & sp_A, sp_B & 5 \\
A3 & sp_A, sp_B, sp_C & 10 \\
A1 & sp_A, sp_B, sp_C, sp_D, sp_G & 20 \\
\hline
\end{tabular}

\subsubsection{Second stage: Application of the algorithm and best selection rules}

The second stage applies the algorithm, evaluates the rules generated, and aims to determine the highest quality selection rules. After the second stage, the rules are included in the database for knowledge generation, in this case, co-occurrence between species. This stage is divided into the following steps (the numbering continues from the first stage): 
(7) Configuration parameters required for the application of the algorithm - Verification of the lower frequency among species to define the minimum support (min_sup), minimum confidence (min_conf), negative minimum lift (negative_min_lift) and positive minimum lift (positive_min_lift) to verify positive and negative rules;

(1)

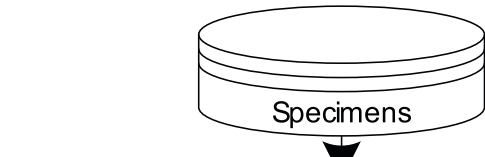

(2)

(3)

(4)

(5)

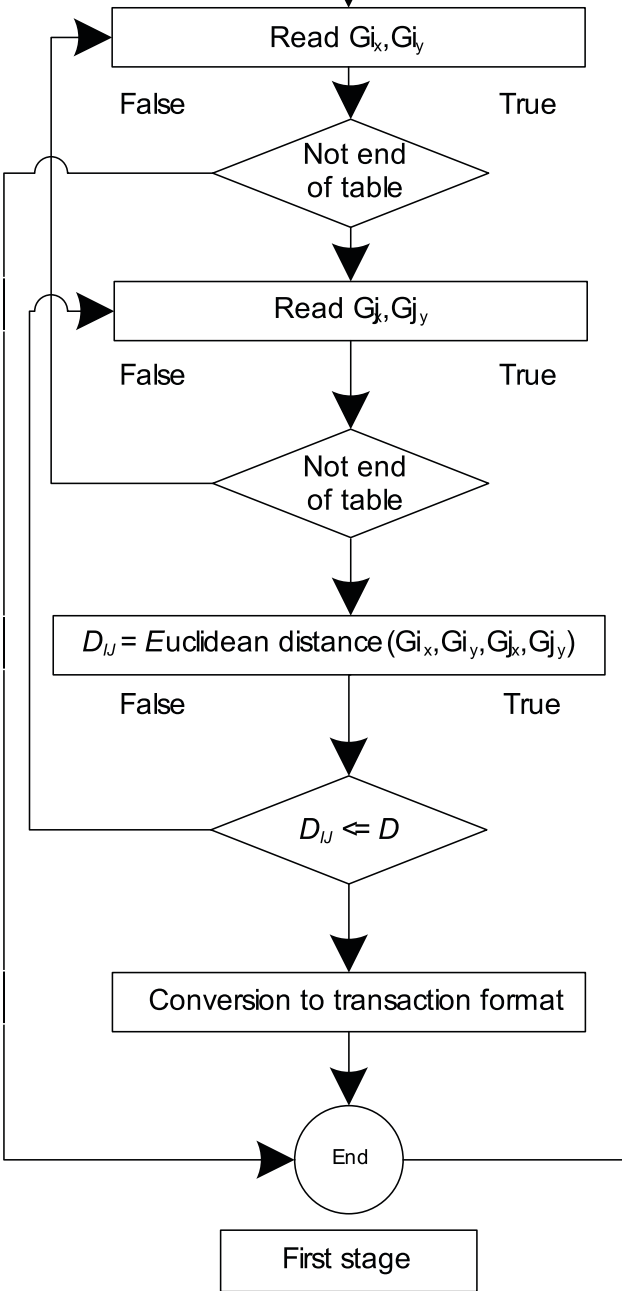

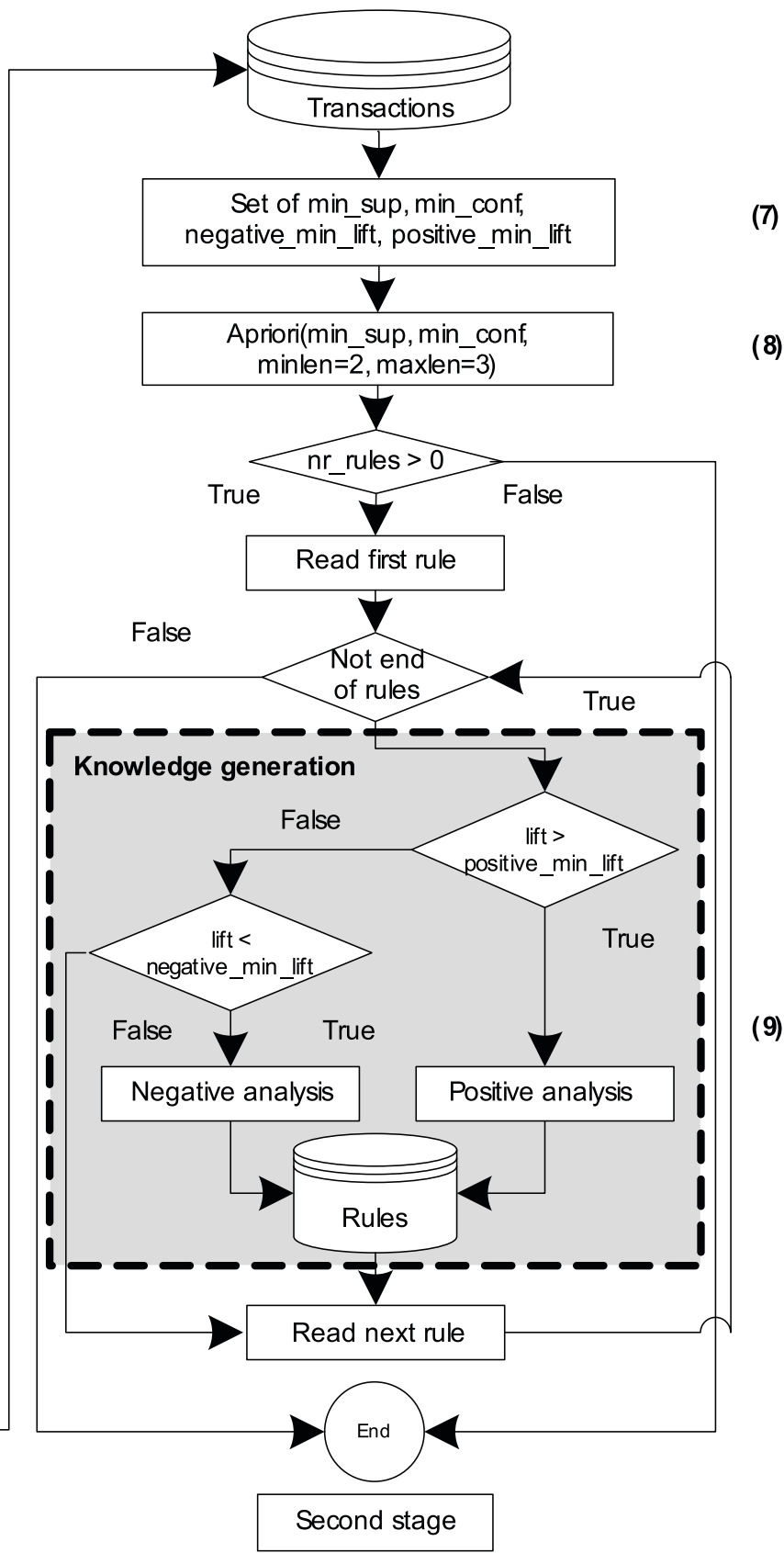

Fig. 2. This figure depicts the steps of the first stage of the method to prepare the data set. The second stage of the method aims to apply the algorithm and best selection rules.

(8) Application of algorithm - Use of Apriori with parameters: min_sup, min_conf, minlen and maxlen. The last two parameters specify the type of analysis between pairs or groups of species;

9) Knowledge generation - Selection of best rules by verification of generated rules, considering a minimum value of confidence and support, testing to assess the type of association observed (positive or negative) and insertion of the rules into the database. The rules are also evaluated in this step according to the values of the metrics used and knowledge generation based on research interests. 
The Algorithm 1 (Alg. 1) was created to verify the details of the implementation of Step 9 of the second stage, to obtain quality rules in pairs and groups of up to 3 species. The objective of each line is described as follows:

- Line 1 defines the set of minimum values for basic quality metrics (support and confidence) for the selection of rules generated;

- Line 2 to 5 initialize counters to quickly verify whether rules were created for each type of analysis;

- Line 6 indicates that the application of the algorithm evaluates patterns between pairs or groups of up to 3 species at the same time (analysis with more species could be done with this parameter);

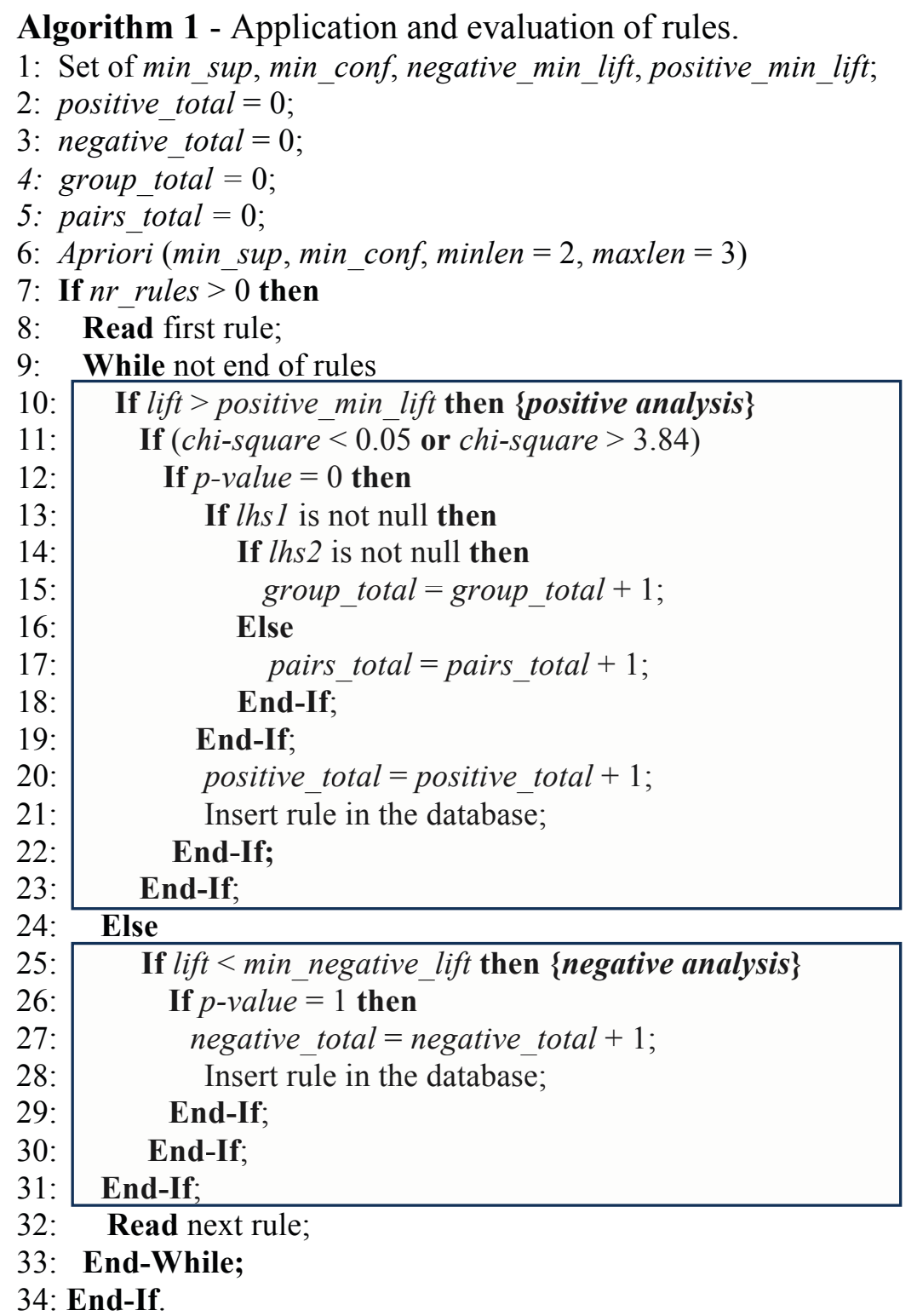

Alg.1. This chart displays the details of the second stage of the method for knowledge extraction based on the following legend: $\min \_$sup $=$minimum support; $\min \_$conf $=$minimum confidence; negative_min_lift $=$negative minimum lift; positive min lift = positive minimum lift; minlen and maxlen setting the minimum and maximum number of elements involved in rules; $n r_{-}$rules $=$number of generated rules; conf $=$confidence; sup_lhs $1=$ first element of left hand side (lhs) of rule; sup_lhs $2=$ second element of left hand side of rule; sup_rhs $=$ element of right hand side or rule (rhs); positive_total = counter of positive rules; negative_total = counter of negative rules; group_total $=$ counter of group rules; pairs_total $=$ counter of pairs rules.

- Line 7 performs a test to verify if rules were obtained, avoiding the tests for positive and negative;

- Line 8 and 9 create the repetition that evaluates all rules generated (temporarily in memory); 


\section{- Positive analysis:}

- From line 10 to line 23, the positive analysis is performed using the lift metric;

- Line 11 verifies acceptable values for independence between the elements of a rule with the metric chi-square;

- Line 12 verifies the probability of items occurring together with metric $p$-value;

- Line 13 is used to confirm that items of a group rule were identified, and Line 14 confirms the rule in case of study with pairs of species;

- Lines 15 and 17 are used to count respective cases;

- In Line 20, the counting positives rules are increased;

- Line 21 is used to insert the rule into the database;

\section{- Negative analysis:}

- In Line 25, the value for negative rules is verified with use of the lift metric;

$\circ$ The value equal to 1 in metric $p$-value in Line 26 indicates independent elements or proves that the occurrence of an item does not affect the occurrence of another;

- In Line 27, the counting is done for negative rules;

- Line 28 is used to insert the rule into the database.

We used the following as parameters that required the application of Apriori: minlen $=2$, maxlen $=3$, these parameters indicate the minimum and maximum number of elements involved in a rule, these values enable the analysis in bivariate spatial patterns (value equal 2) or multivariate mode (value equal 3 ), groups of species, simultaneously, these values may be changed according to the purpose of the study; support, based on the value of the species with the lowest frequency, to not eliminate any species from the analysis; and minimum confidence $=0.3$, this value was arbitrarily specified to obtain relevant rules where confidence of finding the second species, when found the first, is at least $30 \%$.

As an additional way to evaluate the quality of our method, we apply Ripley's K-function statistics with the proposed method over the same species study cases and the same parameters (radius) for a bivariate plot analysis, with $95 \%$ confidence envelopes estimated from 100 simulations.

The method was implemented with R (R Development Core Team, 2012) and Apriori with package Arules (Hahsler et al., 2005). The database used was Postgresql.

\section{Experiment results}

Three case studies were produced to verify the efficiency of the method, identifying positive and negative co-occurrences with pairs or groups of species and associating these occurrences with the habitats displayed in Fig. 7. The tests used maximum distances of up to 5 and 20 meters between the specimens. The application of the method resulted in transactions containing 18,686 and 19,647 items, respectively, highlighting the potential for knowledge extraction from large volumes of data. The studies of species co-occurrence follow the current trend of analyzing pairs of species, similar to the model presented by Veech (Veech, 2013) to classify species associations as negative, positive or random. It is possible to further improve the results obtained using subjective measures of interest, such as visualization (Tan, 2007). For example, Fig. 3 (a,b), 4 (a,b), 5 (a) and 6 (a,b) were created to demonstrate the spatial distribution of some species in scatterplots. Graduation in the axis of the figures indicates the size of the plot of BCI (1000 x 500 meters). In scatterplots, ellipses were used to highlight 
the concentration distribution of data. In other cases, the smoother linear regression better indicates the distribution of spatial data.

\subsection{Positive Species Association}

As results were not observed, the rules characterizing co-occurrence patterns from a distance of 5 meters, were both positive as for negative tests, but at distance of 20 meters, the application of the method resulted in 8 rules involving 11 species. These rules are displayed in Table 4, numbered from 1 to 8. In Fig. 3(a), the application of the method reveals that the center of distribution for species Virola multiflora and Xylopia macrantha is higher on habitat Slope (S); totaling $44.8 \%$ of both their occurrences. The metrics for this rule indicated that 4\% (support) of the data set was found for both species, and 60\% (confidence) of the cases found Virola multiflora and Xylopia macrantha at a maximum distance of 20 meters. In Fig. 3(b), 50\% of cases that had the occurrence of species Terminalia oblonga also observed occurrences of Ocotea whitei, totaling 3\% of the data set. We apply a threshold a lift $>=2.0$ (Fig. 8(b)), since any positive values would be enough for such assessment (Fig.

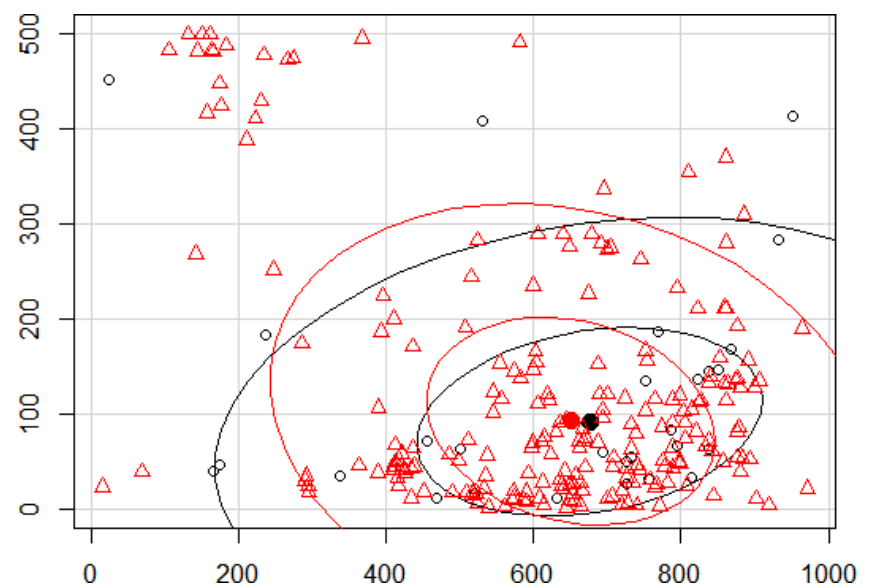

(a)

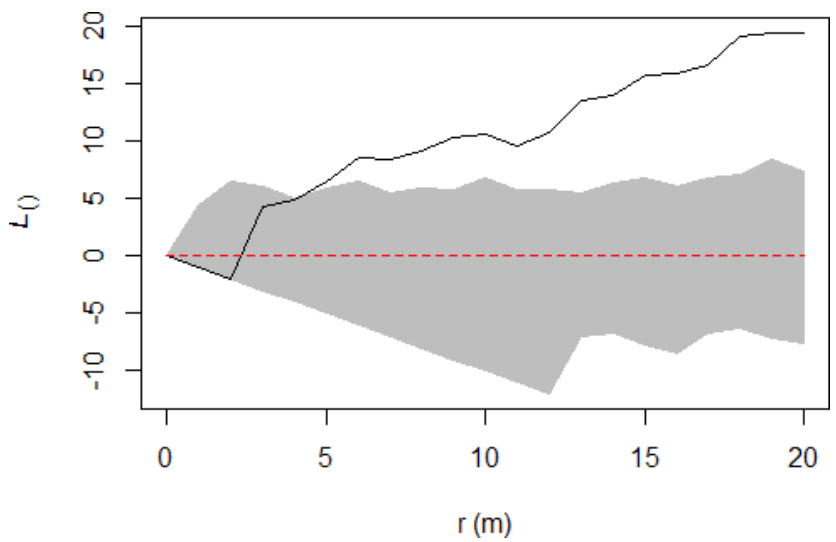

(c)

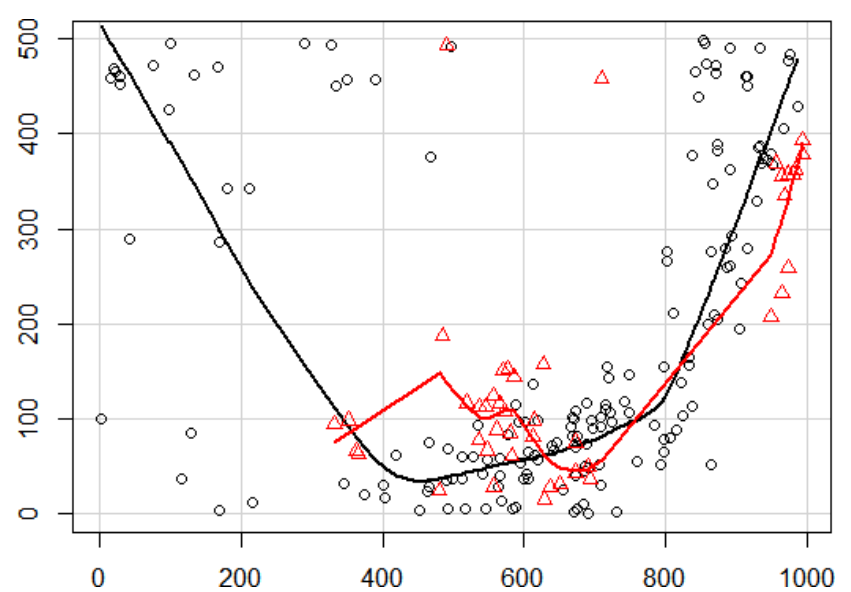

(b)

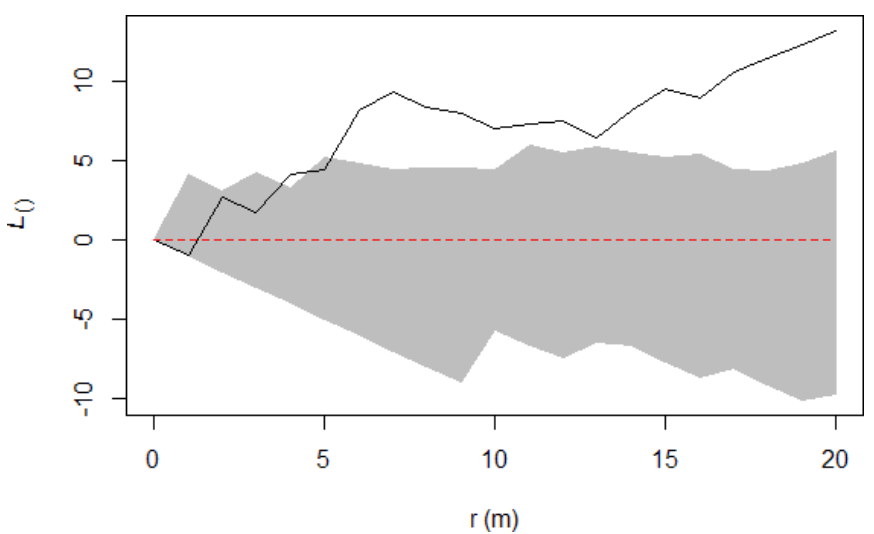

(d)

Fig. 3. Spatial distribution for positive species co-occurrence - comparison of results obtained with application of the proposed method (Fig. 3(a,b)) and bivariate ripley's K-function (Fig. 3(c,d)), values above the upper confidence envelope indicate positive association, between Virola multiflora (black) and Xylopia macrantha (red) (Fig. 3(a,c)); and. Terminalia oblonga (red) and Ocotea whitei (black)

(Fig. 3(b,d)).

8). To facilitate the visualization of the results, instead of using the centers of the distributions, linear 
regression was used in the scatterplot displaying similar values in both slope and low plateau habitats. The $p$-value for all rules was 0 .

\subsection{Negative Species Association}

For a lift value $<=0.7$, a high-value co-occurrence negative, 10 rules were generated for 15 species. These rules are displayed in Table 4 and numbered from 8 to 18. Two of them are displayed in Fig. 4(a)(b), presenting a negative correlation. The p-value for all rules was 1. Fig. 4(a) reveals Gustavia Superba (black) has a higher incidence in young forest habitats and Socratea exorrhiza (red) on the low plateau. Both species occur together in only $13 \%$ of the total. Only one specimen of Socratea exorrhiza

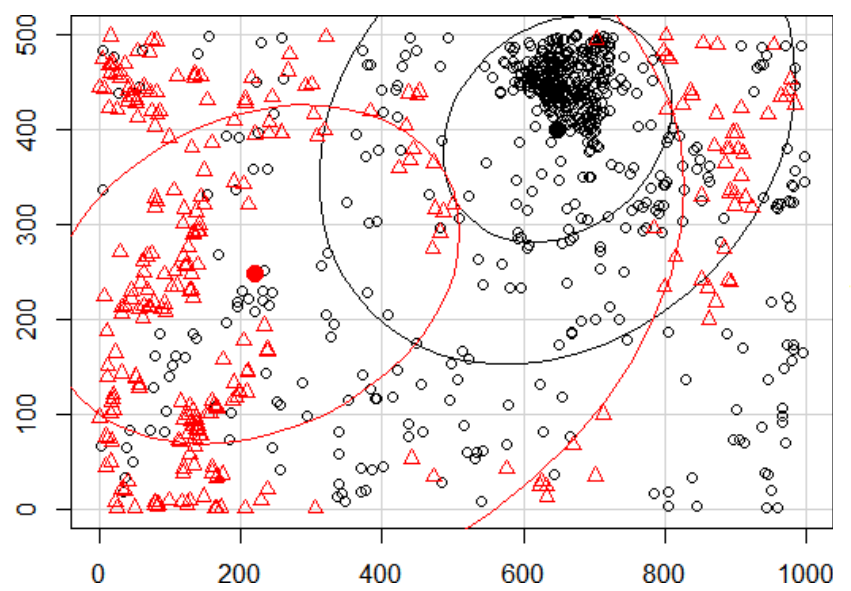

(a)

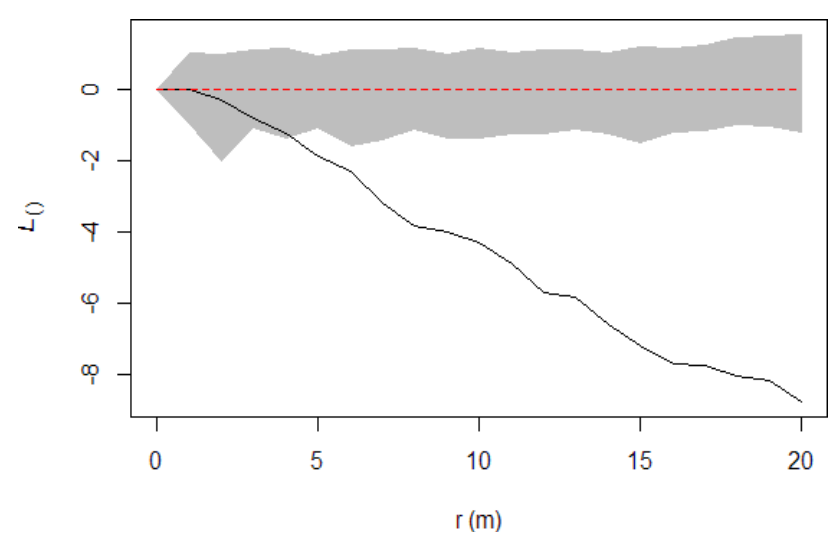

(c)

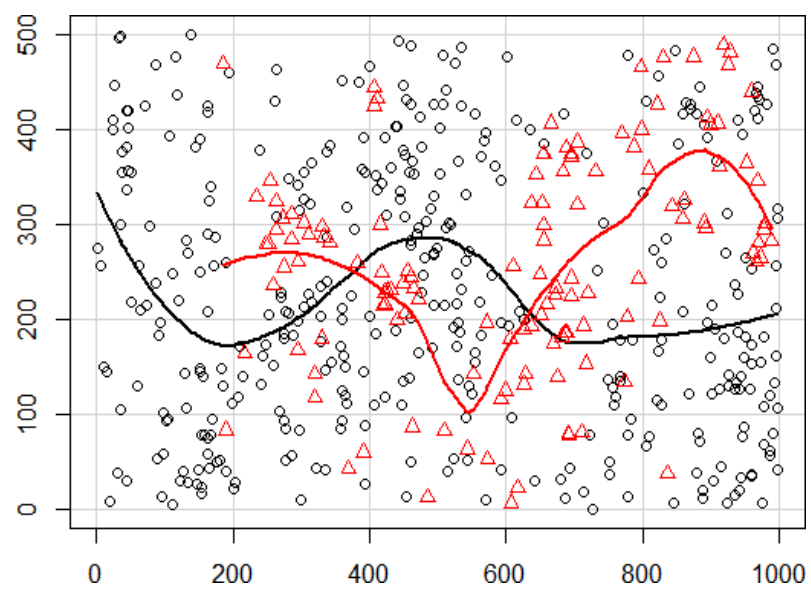

(b)

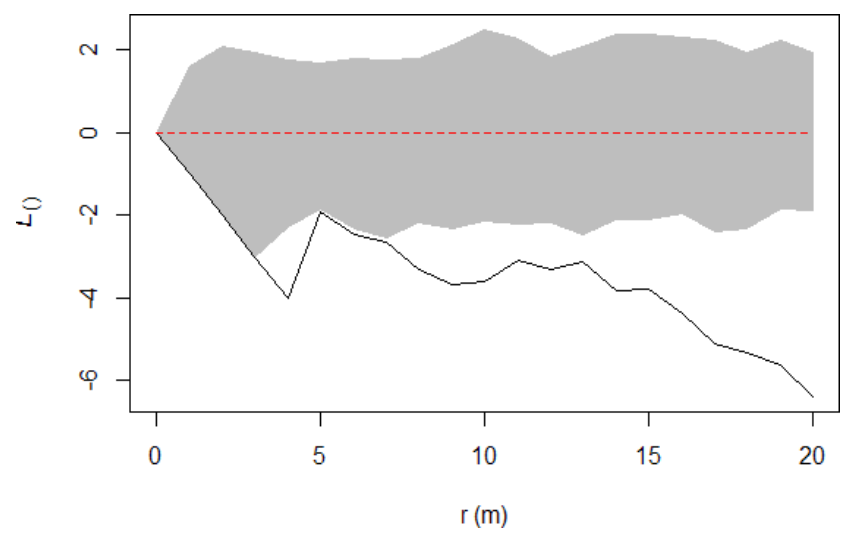

(d)

Fig. 4. Spatial distribution for negative species co-occurrence - comparison of results obtained with application of the proposed method (Fig. 4(a,b)) and bivariate ripley's K-function (Fig. 4(c,d)), values below the upper confidence envelope indicate negative association, between Socratea exorrhiza (red) and Gustavia superba (black) (Fig. 4(a,c)); and. Tetragastris panamensis (black) and Triplaris cumingiana (red) (Fig. 4(b,d)). Dashed horizontal line provides a reference under complete spatial randomness (Fig. 4(c,d)).

was found in the young forest. Fig. 4(b) indicates the wide distribution of species Tetragastris panamensis (black) and Triplaris cumingiana (red), contrary to their preferences in terms of habitat. Both species occur together only $13.8 \%$ of the time at a maximum distance of 20 meters. 


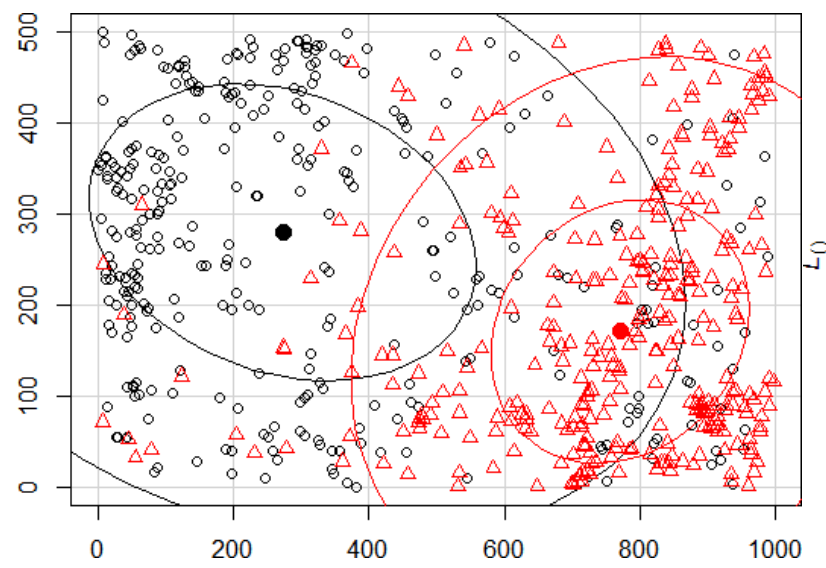

(a)

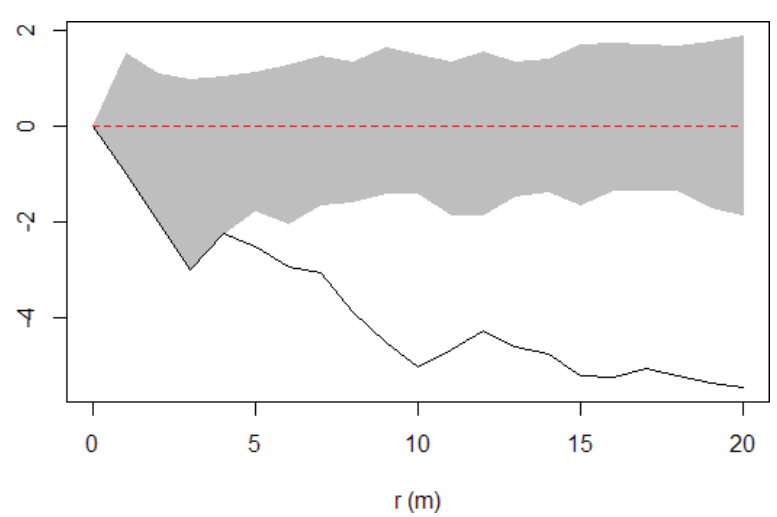

(b)

Fig. 5(a). Spatial distribution for negative species co-occurrence - comparison of results obtained with application of the proposed method (Fig. 5(a)) and bivariate ripley's K-function (Fig. 5(b)), values below the upper confidence envelope indicate negative association, between Cordia bicolor (black) and Drypetes standleyi (red). Dashed horizontal line provides a reference under complete spatial randomness (Fig. 5(b)).

The method was also efficient for detecting negative associations with species that have a minimum difference between frequencies, such as Cordia bicolor and Drypetes standleyi, at only 0.05 in this case (Fig. 5(a,b)).

\subsection{Grouping of Species}

Fig. 6(a) displays the occurrence of species Ocotea whitei (black), Virola multiflora (red), and

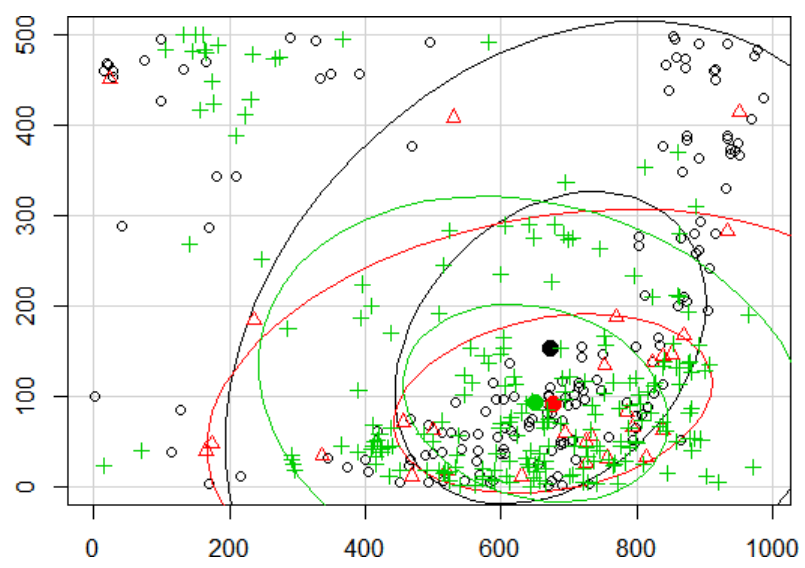

(a)

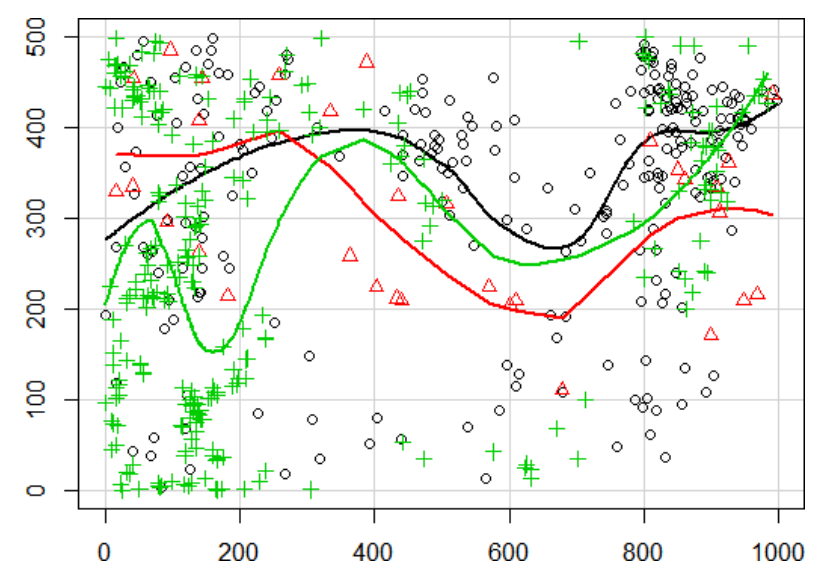

(b)

Fig. 6(a). Spatial distribution for positive species co-occurrence between Ocotea whitei (black), Virola multiflora (red) and Xylopia macrantha (green). Fig. 6(b). The figure includes Inga goldmanii (red), Socratea exorrhiza (green) and Beilschmiedia pendula (black).

Xylopia macrantha (green) highlighted in the center of the distribution of occurrences of the three species. As knowledge was generated, we identified it in the slope habitat. After we found the first two 
species, there was a $70 \%$ chance of finding a third at a distance of up to 20 meters in $2 \%$ of the transactions. Fig. 6(b) indicates the distribution of species Inga goldmanii (red), Socratea exorrhiza (green) and Beilschmiedia pendula (black) along the plot. The metric confidence reveals that when the first two species were found, in $83 \%$ of cases a third species was also found, with their distributions highlighted by smooth curves. Rules of species groups are presented in Table 4 from Line 19 to 27. 


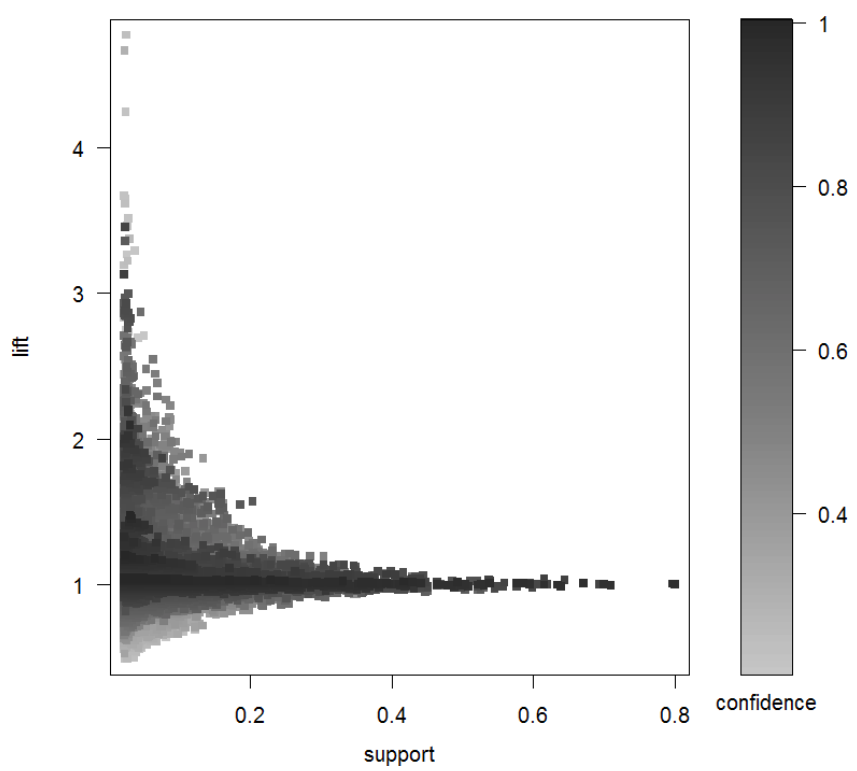

Fig. 7. Distribution of main measures: lift, support and confidence for all rules generated by applying the method to the distance of 20 meters.

Table 3

List of species that presented co-occurrence and displayed in Table 4

\begin{tabular}{lll}
\hline Species & Species code & No.stems \\
\hline Adelia triloba & ade_tri & 64 \\
Attalea butyracea & att_but & 32 \\
Beilschmiedia pendula & bei_pen & 249 \\
Casearia sylvestris & cas_syl & 38 \\
Drypetes standleyi & dry_sta & 316 \\
Guarea guidonia & gua_gui & 352 \\
Guatteria dumetorum & gua_dum & 164 \\
Gustavia superba & gus_sup & 604 \\
Inga goldmanii & ing_gol & 32 \\
Inga thibaudiana & ing_thi & 38 \\
Lacmellea panamensis & lac_pan & 55 \\
Ocotea whitei & oco_whi & 162 \\
Perebea xanthochyma & per_xan & 27 \\
Platypodium elegans & pla_ele & 30 \\
Poulsenia armata & pou_arm & 567 \\
Pourouma bicolor & pou_bic & 20 \\
Quararibea asterolepis & qua_ast & 728 \\
Pterocarpus rohrii & pte_roh & 52 \\
Socratea exorrhiza & soc_exo & 273 \\
Spondias mombin & spo_mom & 37 \\
Terminalia oblonga & ter_obl & 44 \\
Tetragastris panamensis & tet_pan & 386 \\
Triplaris cumingiana & tri_cum & 131 \\
Trophis caucana & tro_cau & 38 \\
Unonopsis pittieri & uno_pit & 178 \\
Virola multiflora & vir_mul & 28 \\
Virola sebifera & vir_seb & 524 \\
Xylopia macrantha & xyl_mac & 215 \\
Zanthoxylum ekmanii & zan_ekm & 139 \\
\hline & & \\
& &
\end{tabular}

Depending on the values of the parameters used in the application of association analysis algorithm, the number of rules obtained can be high. So, Fig. 7 presents a scatter plot using support and confidence on the axes, in addition with a measure lift, with the parameters used in the case studies, which were 
generated 78,592 rules. It can be seen that rules with high lift have a relatively low support. Thus facilitating the selection of the best rules.

\section{Interpretation of Results}

To facilitate analysis of the results two tables were created. Table 3 displays the 29 species present in the results, their codes and total stems of each species. Fig. 8, based on (Harms et al., 2001), illustrates the distribution of specimens per habitat, organized in 1250 quadrants of 20 meters x 20 meters in a 50 ha area. The identification of habitat types facilitates understanding the results generated. Table 4 shows the main rules obtained by applying the method to the distance of 20 meters, along with the results of key metrics. Positive species association rules, with high lift value, are numbered 1-8; negative species association rules, with lower values than 1, from 9-18; and the positive rules of species groups 19-27.

There are studies explaining co-occurring species, so the patterns produced by our method may be interpreted with hypotheses reported in others studies that consider the influence of coexistence mechanisms, such as: interactions with neighbors of the same (conspecific) and other (heterospecific) species (Comita, Muller-Landau, Aguilar, \& Hubbell, 2010), responses related to taxonomic or functional identity of neighbouring species (Uriarte et al., 2004), association (positive) and segregation (negative) interspecific species using Point Pattern Analysis (Wiegand et al., 2012), (Wiegand \&

Table 4

Metrics for the main co-occurrences patterns obtained using the method.

\begin{tabular}{|c|c|c|c|c|c|c|}
\hline Rules & Antecedent $\rightarrow$ Consequent & Sup & Conf & Lift & Chi & Habitat \\
\hline 1 & vir_mul $\rightarrow x y l \_m a c$ & 0.04 & 0.60 & 2.44 & 833.0 & slope \\
\hline 2 & ter_obl $\rightarrow$ oco_whi & 0.03 & 0.50 & 2.32 & 657.3 & slope/low plateau \\
\hline 3 & pou_bic $\rightarrow$ soc_exo & 0.03 & 0.79 & 2.83 & 1066.1 & low plateau \\
\hline 4 & ing_thi $\rightarrow$ pte_roh & 0.02 & 0.30 & 2.55 & 509.2 & low plateau \\
\hline 5 & tro_cau $\rightarrow$ oco_whi & 0.03 & 0.54 & 2.51 & 806.1 & slope \\
\hline 6 & vir_mul $\rightarrow$ oco_whi & 0.03 & 0.52 & 2.44 & 704.5 & slope/low plateau \\
\hline 7 & per_xan $\rightarrow$ soc_exo & 0.03 & 0.67 & 2.43 & 811.3 & low plateau \\
\hline 8 & ing_thi $\rightarrow$ zan_ekm & 0.03 & 0.45 & 2.27 & 626.5 & low plateau \\
\hline 9 & soc_exo $\rightarrow$ gus_sup & 0.08 & 0.30 & 0.67 & 705.1 & - \\
\hline 10 & tri_cum $\rightarrow$ tet_pan & 0.08 & 0.36 & 0.68 & 595.0 & - \\
\hline 11 & $s p \bar{o} \_m o m \rightarrow \overrightarrow{v i r}$ seb & 0.02 & 0.35 & 0.53 & 603.1 & - \\
\hline 12 & ade_tri $\rightarrow$ tet_pan & 0.04 & 0.33 & 0.63 & 387.6 & - \\
\hline 13 & $a t t \_b u t \rightarrow v i r \_s e b$ & 0.03 & 0.43 & 0.64 & 351.5 & - \\
\hline 14 & uno_pit $\rightarrow$ gus_sup & 0.09 & 0.30 & 0.66 & 858.6 & - \\
\hline 15 & pla_ele $\rightarrow$ gua_gui & 0.02 & 0.33 & 0.66 & 177.1 & - \\
\hline 16 & cas_syl $\rightarrow$ pou_arm & 0.03 & 0.31 & 0.67 & 174.8 & - \\
\hline 17 & $z a n \_e k m \rightarrow g u s \_s u p$ & 0.06 & 0.31 & 0.68 & 407.0 & - \\
\hline 18 & lac_pan $\rightarrow$ pou_arm & 0.04 & 0.33 & 0.70 & 192.7 & - \\
\hline 19 & oco_whi, vir_mul $\rightarrow x y l \_m a c$ & 0.02 & 0.70 & 2.87 & 715.8 & slope \\
\hline 20 & ing_gol, soc_exo $\rightarrow$ bei_pen & 0.02 & 0.83 & 2.34 & 577.2 & slope/low plateau \\
\hline 21 & uno_pit, vir_mul $\rightarrow x y l \_m a c$ & 0.02 & 0.85 & 3.46 & 1104.7 & slope/low plateau \\
\hline 22 & ter_obl, xyl_mac $\rightarrow$ oco_whi & 0.02 & 0.72 & 3.36 & 1023.0 & slope/low plateau \\
\hline 23 & poūarm, pou_bic $\rightarrow$ soc_exo & 0.02 & 0.87 & 3.13 & 880.4 & low plateau \\
\hline 24 & $d r y \_s t a, v i r \_m u l \rightarrow x y l \_\overline{m a c}$ & 0.03 & 0.74 & 3.00 & 1025.8 & low plateau \\
\hline 25 & gua_dum, vir_mul $\rightarrow x \bar{y} l \_m a c$ & 0.02 & 0.72 & 2.93 & 762.0 & slope \\
\hline 26 & pou_bic, qua_ast $\rightarrow$ soc_exo & 0.02 & 0.81 & 2.93 & 886.4 & low plateau \\
\hline 27 & pou_bic, vir_seb $\rightarrow$ soc_exo & 0.03 & 0.80 & 2.90 & 877.9 & low plateau \\
\hline
\end{tabular}

Moloney, 2004). 


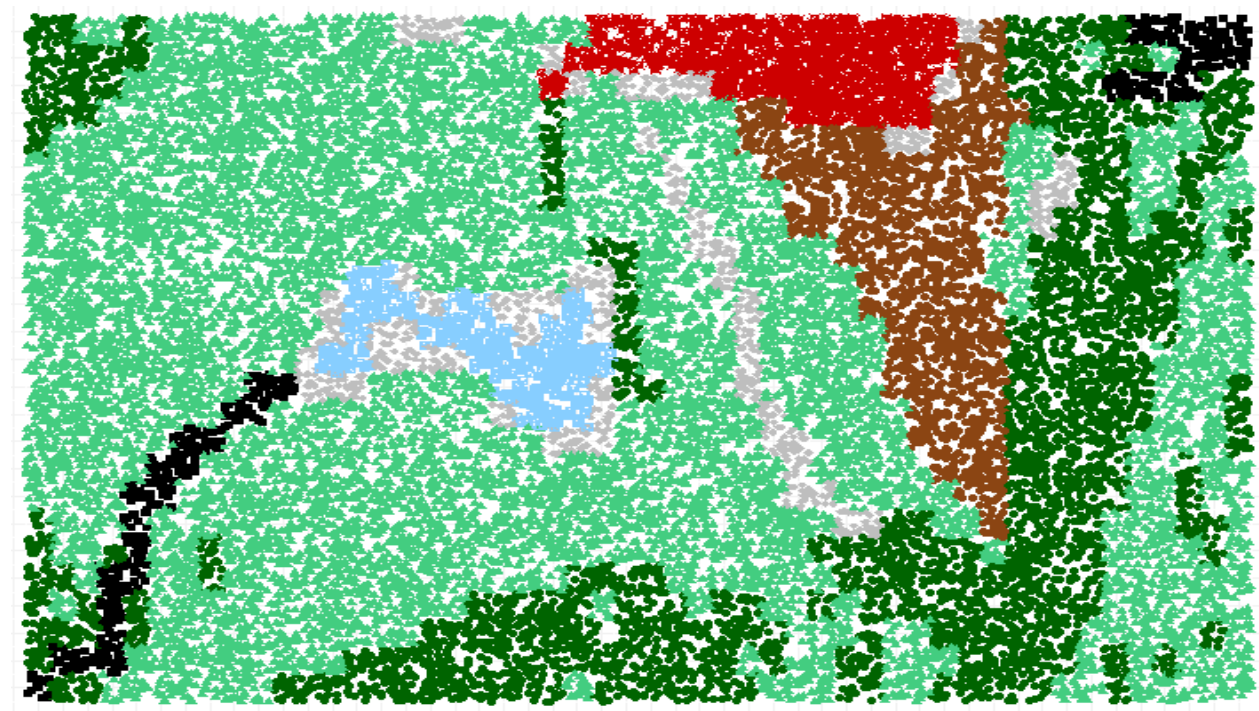

Fig. 8. The distribution of specimens with a Diameter at Breast Height (DBH) greater than 100 millimeters, per habitat in BCI. There are seven habitat types identified: W - swamp (blue), L - low plateau (light green), H - high plateau (brown), S - slope (dark green), T - stream side (black), Y - young forest (red), and M - mixed habitat (gray), based on (Harms et al., 2001).

\section{Discussion and conclusions}

The demand for analyzing large databases has triggered a search for new methods, as has occurred in other fields. Ecology requires tools that can perform knowledge extraction automatically so that this knowledge supplements the work of its researchers. We considered the application of data mining in this study primarily due to its efficiency in knowledge extraction for databases and secondly to facilitate the identification of patterns experts can investigate further. Therefore, data mining was evaluated in terms of its application in the analysis of environmental data. This study used data mining to obtain information about the occurrence of species. We adapting the traditional association rules for application to data obtained from floristic inventories and simultaneous analysis of species occurrences in pairs and groupings.

The novelty of our approach lies in the development of a multi-scale method for the analysis of cooccurrence species, computing by euclidean distance between all events (trees) in a defined radius and the selecting frequent items (species) that occur together. Point-process models applications that consider only pairwise interactions and the limited ability to separate scales (Detto \& Muller-Landau, 2013) become unviable for tropical forests formed with species-rich communities (X. Wang et al., 2010). Our approach is a multi-species method that allows the simultaneous analysis of pairs and groups of species, identifying species that indicate a positive and negative co-occurrence in the same analysis. Identifying groups may allow a better characterization of the vegetation type in a region or serve as indicators of the presence of other species. This method not necessity selection of pair species as in bivariate analysis with K-function, helping resolve relates to studies involving many species. As far as we know, this method is the first automated tool to produce exhaustive co-occurrence and lists of two or more species.

For these results to be achieved, experiments that cover three case studies have been performed on a database containing data plots and, specified in an approach based on the analysis of association rules, using the distances of 5 and 20 meters between the specimens as a determinant factor for the definition of transactions analyzed and the evaluation of preferred habitats. The opposite occurred in species where the algorithm identified opposite habitat preferences. The results obtained from case studies of 
pairs and groups of species demonstrated that knowledge could be extracted according to positive and negative correlation observed between species, crossing the occurrence of species with habitat.

This paper considers that the proposed method can impact the ecology for the agility achieved with the appropriate analysis to large databases and the inclusion of data mining in the process of generating knowledge and facilitating revealing insights into species that have some type of co-occurrence, given that different research areas that have applied the method achieved interesting results, as cited in the introduction. The method may also be used as an experimental environment to reveal insights through data that can be better investigated by specialists, such as interspecific associations of plant species (Lan et al., 2012) caused by the shade influence (Uriarte et al., 2004).

Further studies are needed to determine how to use the method to assist in proving existing hypotheses in the field of plant communities, such as intraspecific competition or surveying microhabitats and for the use of biotic variables. Another point of discussion is the selection of another existing metric to evaluate the generated association rules. The metrics used in this study were sufficient, but others can be tested for this type of application. The last point for future studies is the inclusion of domain knowledge in the process, considering the reduction of the number of rules.

\section{Acknowledgments}

We would like to thank the Centre for Tropical Forest Science of the Smithsonian Tropical Research Institute for providing data for this research. The BCI forest dynamics research project was made possible by the National Science Foundation grants to Stephen P. Hubbell: DEB-0640386, DEB-0425651,DEB-0346488, DEB-0129874, DEB-00753102, DEB-9909347，DEB-9615226，DEB-9615226，DEB-9405933，DEB-9221033，DEB-9100058，DEB-8906869，DEB8605042,DEB-8206992, DEB-7922197, support from the Centre for Tropical Forest Science, the Smithsonian Tropical Research Institute, the John D. and Catherine T. MacArthur Foundation, the Mellon Foundation, the Celera Foundation, and numerous private individuals, and through the hard work of over 100 people from 10 countries over the past two decades. The plot project is part of the Centre for Tropical Forest Science, a global network of large-scale demographic tree plots. We are grateful to Prof. Mário Luís Garbín of Federal University of Espírito Santo for suggestions.

\section{References}

Abdelhamid, N., Ayesh, A., \& Thabtah, F. (2014). Phishing detection based Associative Classification data mining. Expert Systems with Applications, 41(13), 5948-5959.

Adomavicius, G., \& Tuzhilin, A. (2005). Toward the next generation of recommender systems: A survey of the state-of-the-art and possible extensions. IEEE Transactions on Knowledge and Data Engineering, 17(6), 734-749.

Aggarwal, C. (2015). Data Mining: The Textbook. New York: Springer International Publishing.

Aggarwal, C. C., Zhao, Y., \& Yu, P. S. (2010). On clustering graph streams. Sdm, (Santiago, Chile), 478-489.

Agrawal, R., Imieliński, T., \& Swami, A. (1993). Mining association rules between sets of items in large databases. ACM SIGMOD Record, 22(2), 207-216.

Baddeley, A., \& Turner, R. (2005). spatstat: An R Package for Analyzing Spatial Point Patterns. Journal Of Statistical Software, 12(6), 1-42.

Baselga, A., \& Araújo, M. B. (2010). Do community-level models describe community variation effectively? Journal of Biogeography, 37(10), 1842-1850.

Besag, J. E. (1977). Comments on Ripley's paper. Journal of the Royal Statistical Society. Series B (Methodological), 39(2), 193-195.

Bivand, R. S., Pebesma, E. J., \& Gómez-Rubio, V. (2008). Applied Spatial Data Analysis with R. (R. Gentleman, K. Hornik, \& G. Parmigiani, Eds.)Use R (Vol. 747248717). Springer.

Brin, S., Motwani, R., \& Silverstein, C. (1997). Beyond market baskets. ACM SIGMOD Record, 26(2), 265-276.

Cil, I. (2012). Consumption universes based supermarket layout through association rule mining and 
multidimensional scaling. Expert Systems with Applications, 39(10), 8611-8625.

Condit, R. (1998). Tropical forest census plots. Berlin, Germany, and Georgetown, Texas: Springer-Verlag and R. G. Landes Company.

Culmsee, H., Schmidt, M., Schmiedel, I., Schacherer, A., Meyer, P., \& Leuschner, C. (2014). Predicting the distribution of forest habitat types using indicator species to facilitate systematic conservation planning. Ecological Indicators, 37(PART A), 131-144.

Debeljak, M., Poljanec, A., \& Ženko, B. (2014). Modelling forest growing stock from inventory data: A data mining approach. Ecological Indicators, 41, 30-39.

Detto, M., \& Muller-Landau, H. C. (2013). Fitting ecological process models to spatial patterns using scalewise variances and moment equations. The American Naturalist, 181(4), E68-82.

Dlamini, W. M. (2011). A data mining approach to predictive vegetation mapping using probabilistic graphical models. Ecological Informatics, 6(2), 111-124.

Drew, L. W. (2011). Are We Losing the Science of Taxonomy? As need grows, numbers and training are failing to keep up. BioScience, 61(12), 942-946.

Flügge, A. J., Olhede, S. C., \& Murrell, D. J. (2014). A method to detect subcommunities from multivariate spatial associations. Methods in Ecology and Evolution, 5(11), 1214-1224.

Gbif. (2010). Global Biodiversity Information Facility. Natural History, 29(March), 1-2. Retrieved from http://www.gbif.org/

Gordon, J. E., \& Newton, A. (2006). Efficient Floristic Inventory for the Assessment of Tropical Tree Diversity: A Comparative Test of Four Alternative Approaches. Forest Ecology and Management, 237, 564-573.

Haase, P. (1995). Spatial pattern analysis in ecology based on Ripley's K-function: Introduction and methods of edge correction. Journal of Vegetation Science, 6(4), 575-582.

Hahsler, M., Gruen, B., \& Hornik, K. (2005, September). arules: Mining Association Rules and Frequent Itemsets. Retrieved May 2, 2013, from http://cran.r-project.org/package=arules

Han, J., Kamber, M., \& Pei, J. (2011). Data Mining: Concepts and Techniques (3rd ed.). San Francisco: Morgan Kaufmann.

Harms, K. E., Condit, R., Hubbell, S. P., \& Foster, R. B. (2001). Habitat association of trees and shrubs in a 50ha neotropical forest plot. Journal of Ecology, 89(6), 947-959.

Hochachka, W. M., Caruana, R., Fink, D., Munson, A., Riedewald, M., Sorokina, D., \& Kelling, S. (2007). DataMining Discovery of Pattern and Process in Ecological Systems. Journal of Wildlife Management, 71(7), 2427.

Hopkins, G. W., \& Freckleton, R. P. (2002). Declines in the numbers of amateur and professional taxonomists : implications for conservation. Animal Conservation, 5(03), 245-249.

Howe, D., Costanzo, M., Fey, P., Gojobori, T., Hannick, L., Hide, W., ... Rhee, S. Y. (2008). Big data: The future of biocuration. Nature, 455(7209), 47-50.

Hubbell, S. P. (1999). Light-Gap Disturbances, Recruitment Limitation, and Tree Diversity in a Neotropical Forest. Science, 283(5401), 554-557.

Hubbell, S. P., Condit, R. S., \& Foster, R. B. (2005). Barro Colorado Forest Census Plot Data.

Inman-Narahari, F., Giardina, C., Ostertag, R., Cordell, S., \& Sack, L. (2010). Digital data collection in forest dynamics plots. Methods in Ecology and Evolution, 1(3), 274-279.

Ji, Y., Ying, H., Tran, J., Dews, P., Mansour, A., \& Michael Massanari, R. (2013). A method for mining infrequent causal associations and its application in finding adverse drug reaction signal pairs. IEEE Transactions on Knowledge and Data Engineering, 25(4), 721-733.

Johnson, S., Domínguez-García, V., Donetti, L., \& Muñoz, M. A. (2014). Trophic coherence determines foodweb stability. arXiv:q-bio.PE.

Kumar, J., Mills, R. T., Hoffman, F. M., \& Hargrove, W. W. (2011). Parallel k-means clustering for quantitative ecoregion delineation using large data sets. Procedia Computer Science, 4, 1602-1611.

Lan, G., Getzin, S., Wiegand, T., Hu, Y., Xie, G., Zhu, H., \& Cao, M. (2012). Spatial Distribution and 
Interspecific Associations of Tree Species in a Tropical Seasonal Rain Forest of China. PLoS ONE, 7(9).

Lancaster, J., \& Downes, B. J. (2004). Spatial point pattern analysis of available and exploited resources. Ecography, 27(1), 94-102.

Lazcorreta, E., Botella, F., \& Fernández-Caballero, A. (2008). Towards personalized recommendation by twostep modified Apriori data mining algorithm. Expert Systems with Applications, 35(3), 1422-1429.

Liao, S., Chen, Y.-J., \& Deng, M. (2010). Mining customer knowledge for tourism new product development and customer relationship management. Expert Systems with Applications, 37(6), 4212-4223.

Lin, Y. C., Huang, Y. M., \& Leu, J. J. Y. (2011). A new logic correlation rule for HIV-1 protease mutation. Expert Systems with Applications, 38(5), 5448-5455.

Liu, B., Hsu, W., \& Ma, Y. (1999). Pruning and summarizing the discovered associations. Proceedings of the Fifth ACM SIGKDD International Conference on Knowledge Discovery and Data Mining - KDD '99, (pp. 125-134, San Diego, CA), 125-134.

Liu, G., Zhang, H., \& Wong, L. (2011). Controlling False Positives in Association Rule Mining. In: Proceedings of the VLDB Endowment, (pp. 145-156, Seattle, WA), 145-156.

Lloyd, C. D. (2006). Local Models for Spatial Analysis. CRC Press.

Loosmore, N. B., \& Ford, E. D. (2006). Statistical inference using the G or K point pattern spatial statistics. Ecology, 87(8), 1925-1931.

Lorena, A. C., Jacintho, L. F. O., Siqueira, M. F., Giovanni, R. De, Lohmann, L. G., De Carvalho, A. C. P. L. F., \& Yamamoto, M. (2011). Comparing machine learning classifiers in potential distribution modelling. Expert Systems with Applications, 38(5), 5268-5275.

Monge, J. A., \& Gornish, E. E. S. (2014). Positive Species Interactions as Drivers of Vegetation Change on a Barrier Island. Journal of Coastal Research.

Natek, S., \& Zwilling, M. (2014). Student data mining solution-knowledge management system related to higher education institutions. Expert Systems with Applications, 41(14), 6400-6407.

Neeson, T. M., \& Mandelik, Y. (2014). Pairwise measures of species co-occurrence for choosing indicator species and quantifying overlap. Ecological Indicators, 45, 721-727.

Nettleton, D. (2014). Chapter 13 - CRM - Customer Relationship Management and Analysis. In Commercial Data Mining (pp. 195-208).

Peña-Ayala, A. (2014). Educational data mining: A survey and a data mining-based analysis of recent works. Expert Systems with Applications.

Perry, G. L. W., Miller, B. P., \& Enright, N. J. (2006). A comparison of methods for the statistical analysis of spatial point patterns in plant ecology. Plant Ecology, 187(1), 59-82.

Pino-Mejías, R., Cubiles-de-la-Vega, M. D., Anaya-Romero, M., Pascual-Acosta, A., Jordán-López, A., \& Bellinfante-Crocci, N. (2010). Predicting the potential habitat of oaks with data mining models and the R system. Environmental Modelling and Software, 25(7), 826-836.

R Development Core Team. (2012). R: A Language and Environment for Statistical Computing. In R Foundation for Statistical Computing Vienna Austria (Vol. 0). Vienna, Austria: R Foundation for Statistical Computing. Retrieved from http://www.r-project.org

Ripley, B. D. (1977). Modelling spatial patterns. J. R. Statist. Soc. B, 39, 172-212.

Swenson, N. G. (2013). The assembly of tropical tree communities - the advances and shortcomings of phylogenetic and functional trait analyses. Ecography, 36(3), 264-276.

Tan, P. (2007). Introduction To Data Mining. Chemistry \& ... (1st ed.). Boston, MA: Addison-Wesley Longman Publishing Co., Inc.

Uriarte, M., Condit, R., Canham, C. D., \& Hubbell, S. P. (2004). A spatially explicit model of sapling growth in a tropical forest: does the identity of neighbors matter. Journal of Ecology, 92|t(2), 348-360.

Veech, J. A. (2013). A probabilistic model for analysing species co-occurrence. Global Ecology and Biogeography, 22(2), 252-260.

Veech, J. A. (2014). The pairwise approach to analysing species co-occurrence. Journal of Biogeography, 41(6), 
1029-1035.

Wang, P. W. P., Shi, L. S. L., Bai, J. B. J., \& Zhao, Y. Z. Y. (2009). Mining Association Rules Based on Apriori Algorithm and Application. 2009 International Forum on Computer Science-Technology and Applications, 1(25-27 Dec. 2009), 141-143.

Wang, X., Wiegand, T., Hao, Z., Li, B., Ye, J., \& Lin, F. (2010). Species associations in an old-growth temperate forest in north-eastern China. Journal of Ecology, 98(3), 674-686. http://doi.org/10.1111/j.13652745.2010.01644.x

Wiegand, T., Huth, A., Getzin, S., Wang, X., Hao, Z., Gunatilleke, C. V. S., \& Gunatilleke, I. a. U. N. (2012). Testing the independent species' arrangement assertion made by theories of stochastic geometry of biodiversity. Proceedings of the Royal Society B: Biological Sciences, 279(1741), 3312-3320.

Wiegand, T., \& Moloney, K. a. (2004). Rings, circles, and null-models for point pattern analysis in ecology. Oikos, 104(2), 209-229.

Wu, X., Kumar, V., Ross Quinlan, J., Ghosh, J., Yang, Q., Motoda, H., ... Steinberg, D. (2008). Top 10 algorithms in data mining. Knowledge and Information Systems, 14(1), 1-37.

Wu, X., Zhu, X., Wu, G.-Q., \& Ding, W. (2014). Data mining with big data. IEEE Transactions on Knowledge and Data Engineering, 26(1), 97-107.

Zhang, Z., Hu, G., Zhu, J., \& Ni, J. (2012). Aggregated spatial distributions of species in a subtropical karst forest, southwestern China. Journal of Plant Ecology, 6(2), 131-140.

Zhao, Y., Cen, Y., Javaheri, S. H., Sepehri, M. M., \& Teimourpour, B. (2014). Data Mining Applications with R. Elsevier. 